\title{
O PROCESSO ESCOLAR ENTRE IMIGRANTES NO RIO GRANDE DO SUL
}

\author{
DOI: http://dx.doi.org/10.1590/2236-3459/71377
}

THE SCHOOL PROCESS BETWEEN IMMIGRANTS IN RIO GRANDE DO SUL

\author{
Renata Brião de Castro \\ Universidade Federal de Pelotas (Ufpel), Brasil
}

Patrícia Weiduschadt

Universidade Federal de Pelotas (Ufpel), Brasil

\section{$\cos 80$}

LUCHESE, Terciane Ângela. O processo escolar entre imigrantes no Rio Grande do Sul. Caxias do Sul: Educs, 2015.

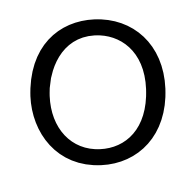

livro O processo escolar entre imigrantes no Rio Grande do Sul é originário da tese de doutoramento da autora Terciane Ângela Luchese. A obra versa sobre a escolarização dos imigrantes de origem italiana na Região Colonial. De forma geral, o estudo trata das iniciativas escolares dos descendentes dos imigrantes. O texto aborda o valor que esses imigrantes atribuem à escolarização de seus filhos e as formas organizativas que se apresentaram na criação das instituições escolares, desde cobranças às autoridades competentes. $\mathrm{O}$ estudo mostra a preferência por escolas públicas. Assim que essas instalavam-se, as chamadas escolas italianas eram fechadas. A perspectiva teórica utilizada pela autora é a da história cultural, a qual tem por objetivo uma problematização das fontes e não somente uma descrição.

O livro está organizado da seguinte maneira: seis capítulos divididos em duas partes; cada parte com três capítulos. O primeiro capítulo faz uma contextualização importante para pensar o espaço da pesquisa. Justino Magalhães (2011), ao escrever sobre o município pedagógico, esclarece que é importante estar atento ao local pesquisado para 
entender suas generalidades ou especificidades.

A primeira parte do estudo, intitulada Dinâmicas de vida e processo escolar na Região Colonial Italiana do Rio Grande do Sul compreende três capítulos. O primeiro trata do processo de ocupação da Região Colonial Italiana. A autora elenca uma série de dados relativos à vinda e instalação dos imigrantes italianos na Serra Gaúcha, desde a saída da Europa até a chegada e colonização dos lotes, apontando que os italianos que decidiam viajar para o Brasil enfrentavam inúmeras dificuldades.

Apesar das dificuldades enfrentadas nos primeiros tempos após sua chegada, os imigrantes conseguiram, em pouco tempo, criar espaços de sociabilidade e de convivência. Dentro desta perspectiva, a autora traz a família como primeiro espaço de sociabilidade. Esta, por sua vez, era numerosa e patriarcal. Os indivíduos que imigraram eram, em grande parte, católicos, e "trouxeram da Itália uma religiosidade com práticas e valores diferenciados daqueles aqui vivenciados". Desta forma, uniam-se num esforço comunitário para construir, nas colônias, capelas, próximas às quais eram criadas outras instituições de igual relevância para os imigrantes, tais como cemitério, escola, salão de festas para a comunidade. (LUCHESE, 2007, p 91).

Nesse momento, é oportuno pensar que as comunidades de imigrantes italianos, ao chegarem ao Brasil, reinventaram tradições (HOBSBAWN; RANGER, 1997). A noção de coletividade está presente nestas comunidades que, muitas vezes, em forma de mutirão e esforço coletivo, envolveram-se na construção de instituições em seu meio, ou ainda em cobrar das autoridades o auxílio de que precisavam.

Na continuidade do primeiro capítulo, segue a autora abordando o desenvolvimento da Região Colonial Italiana, sobretudo dos atuais municípios de Caxias do Sul, Bento Gonçalves e Garibaldi. Nesse sentido, são elencadas as atividades comerciais dos municípios, bem como as profissões, a instalação de redes telefônicas, jornais, bancos, cinemas, construção de ferrovias. Além disso, o texto traz uma reflexão sobre os momentos de sociabilidade deste grupo, sendo a família o primeiro ambiente de sociabilidade. Um costume comum entre os imigrantes e seus descendentes eram os filós, hábito trazido da Itália que consistia no encontro entre famílias vizinhas. No que diz respeito à religiosidade, a predominância era a religião católica, entretanto haviam outras, como a metodista.

Os imigrantes que vieram para o Brasil falavam diferentes dialetos e tinham hábitos de vida diferenciados. Porém, ao se estabelecerem num país diferente do seu, buscaram apoiar-se, criando, neste contexto, as sociedades de mútuo socorro, com a função de proteger os imigrantes (LUCHESE, 2007). Desta maneira, Luchese elenca as sociedades de mútuo socorro fundadas nos três municípios, cujas finalidades, na maior parte das vezes, incluíam assuntos relativos à escolarização. Ainda sobre a sociabilidade dos imigrantes italianos, surgiram bandas de músicas e clubes recreativos.

Conforme Poutignat e Streiff-Fenart (2011), uma das características dos grupos étnicos é a crença na comunidade de origem em comum. Neste contexto, a ideia de serem descendentes de italianos, emigrados de uma Itália em profunda crise econômica. Pode-se pensar no que Anderson (2008) escreve sobre as comunidades imaginadas. Embora o autor se refira, de forma mais específica, às nações, pode-se pensar para comunidades menores. Para Anderson (2008, p. 33), "[...] qualquer comunidade maior que a aldeia primordial do contato face a face (e talvez mesmo ela) é imaginada [...]". As comunidades se distinguem pela forma como são imaginadas. 
No capítulo dois, da primeira parte do livro, é abordado o processo escolar na região estudada. Como elemento principal, a autora observa que a escola pública foi a preferência dos imigrantes italianos preocupados com a educação de seus descendentes. Em outras bibliografias consultadas e referenciadas por Luchese, os autores afirmam que os italianos vindos para o Brasil atribuíam pouca importância à educação. Nesse momento, a autora traz dados referentes à alfabetização dos imigrantes que vieram para o Brasil, assim como algumas taxas de alfabetização na Itália. Ainda, são elencadas informações sobre os índices de alfabetização nos municípios da Região Colonial Italiana.

Nesse ponto, o estudo de Luchese traz uma série de dados que convergem na direção da importância concedida à educação por parte dos imigrantes. Um ponto importante levantado pela autora é o de que não devem ser desconsideradas as condições de vida desses imigrantes, ao analisar os aspectos da escolarização. Em solicitações ao governo, lembravam com frequência os benefícios que a escolarização traria para seus filhos. Estas solicitações evidenciam o quanto os italianos, não só os que imigraram para o Rio Grande do Sul, mas também os que estavam no estado de Santa Catarina, valorizavam a escolarização e empenhavam-se para isso. Para melhor organizar o texto sobre as escolas públicas, a qual era a mais solicitada, a autora realiza uma periodização em dois momentos: o primeiro do início da colonização, de 1875 até 1890 , quando as iniciativas escolares tinham como característica as escolas isoladas, e o segundo de 1890 até 1930, quando o município de Caxias do Sul passou a ter uma Escola Complementar destinada à formação de professores. No que se refere às subvenções, estas eram dadas com a condição de que o ensino fosse na língua vernácula. Essa prática de subvencionar aulas fazia parte de uma política pública educacional. (LUCHESE, 2007).

Ainda no capítulo dois, abordam-se os colégios elementares. Inicialmente, é trazido um panorama mais geral sobre esses colégios e depois a ênfase recai na Região Colonial Italiana. Para a autora, o processo de escolarização no espaço pesquisado foi impulsionado por diversos setores da sociedade e também da iniciativa pública. Os imigrantes não tiveram um único tipo de escola.

No último item da parte um do livro, o capítulo três trata das outras iniciativas escolares na região. Inicia-se o texto abordando as escolas italianas, importantes na difusão do sentimento de italianitá entre os seus descendentes. Essas escolas italianas, de acordo com a autora, ofereciam aulas elementares, nas quais se aprendia a ler, escrever e as primeiras operações matemáticas. As escolas situadas na zona urbana geralmente eram organizadas pelas sociedades de mútuo socorro, já as localizadas na área rural existiam por iniciativa da própria comunidade. Conforme a autora, essas últimas eram escolas que tinham como professor alguém da comunidade que se dedicava a tal função. A maioria desses professores exerciam outra atividade na comunidade que não somente a docência.

Nos relatórios dos cônsules italianos no Brasil, observa-se a preocupação com a falta de instrução entre os colonos. Para a autora, uma questão importante a se considerar no que tange as escolas étnicas era a língua, uma vez que os descendentes desconheciam o italiano, falavam em dialetos, o português era considerado importante para a sobrevivência na nova pátria.

As escolas étnicas eram justificadas pela ausência de escolas públicas. Outro assunto presente são as congregações que surgiram na Região Colonial Italiana. Luchese escreve acerca dessas e sua relação com a escolarização. As escolas paroquiais também 
são abordadas pela autora, essas eram iniciativas do vigário local que se empenhava em construir um espaço para a comunidade.

A parte dois do livro, intitulada Culturas escolares nas escolas públicas da região colonial italiana, é composta pelos capítulos quatro, cinco e seis. No capítulo quatro, abordam-se as escolas localizadas na Região Colonial Italiana a partir de vários aspectos da cultura escolar. O conceito de cultura escolar vem sendo trabalhado de forma bastante intensa pelos pesquisadores da História da Educação, sobretudo a partir dos estudos de Julia (2001). Para Viñao Frago (1995), é mais adequado falar em culturas escolares, no plural, pois, para o autor, a cultura escolar é um conjunto de aspectos institucionalizados, que caracterizam a escola como organização e possuem vários níveis. Viñao Frago explica o termo "conjunto de aspectos institucionalizados", o qual inclui práticas e condutas, modos de vida, hábitos e ritos, entendendo a cultura escolar como toda a vida escolar, ressaltando que alguns de seus aspectos são mais relevantes que outros, dando os contornos e a definindo (1995, p. 68). Para o autor, a cultura escolar é toda a vida escolar.

A autora aborda os tempos escolares, os índices de matrícula e frequência das cidades de Caxias do Sul, Bento Gonçalves e Garibaldi, estabelecendo conexões. Além disso, há dados sobre a organização do calendário escolar e horários de entrada e saída dos alunos, fazendo reflexões sobre o tempo escolar, condicionado ao tempo social. Os exames finais e a celebração desses também foram contemplados neste capítulo, que aborda as expectativas e festejos das comunidades nesses momentos. Outro tópico referese à arquitetura e ao espaço escolar, trazendo imagens de algumas instituições escolares, abordando as escolas isoladas e os colégios elementares. As festividades escolares, as quais se configuram como momentos de sociabilidade na localidade, também recebem atenção nesse capítulo.

O quinto capítulo, por sua vez, trata dos docentes no espaço geográfico pesquisado. São abordadas as trajetórias de vida de alguns professores que atuaram na Região Colonial Italiana. Ainda neste capítulo, disserta-se sobre como os professores eram admitidos, como era feito o provimento das escolas, quais eram as atribuições dos professores, ressaltando que as comunidades participavam indicando, por vezes, a professora ou professor de sua preferência. Para finalizar, aborda-se sobre a inspeção escolar, na qual ganhou relevo a figura dos inspetores.

Finalizando o livro, o capítulo seis trata das práticas e dos saberes escolares, realizando uma reflexão acerca do conceito de cultura escolar. Os métodos empregados para o ensino são abordados neste ponto do estudo, com ênfase no método intuitivo. As disciplinas escolares compõem outro item estudado: a autora elenca como deveria ser ministrada cada disciplina. Chervel (1990) analisa a história das disciplinas escolares. Para o autor, "é às circunstâncias de sua gênese e à sua organização interna que as disciplinas escolares devem o papel, subestimado, mas considerável, que elas desempenham na história do ensino e na história da cultura". (1990, p. 221).

Neste último capítulo, a autora escreve sobre o ensinar e o aprender em português, refletindo sobre a escola ter sido um meio difusor da cultura, cumprindo o papel de ensinar em português a fim de evitar o que ocorria nas zonas de colonização alemã, ou seja, haver pessoas que não sabiam o idioma português. Nesse sentido, a escola era importante para a construção da nacionalidade. A autora nota que a escola foi para alguns alunos o local onde se deu o choque cultural, tendo as crianças o primeiro contato com o português. Nesse 
ponto do estudo, a autora faz reflexões acerca da nacionalização. Os livros didáticos e manuais escolares são outro tópico estudado, elencando alguns dos livros utilizados na região pesquisada, assim como a distribuição desses livros.

Ao longo de todo o livro, há imagens que auxiliam na análise e compreensão do estudo por parte dos leitores. Ao ler a obra de Luchese, nota-se a relevância de seus estudos para a temática da escolarização entre os imigrantes, em especial os de origem italiana no Estado do Rio Grande do Sul, e mais especificamente na Região Colonial Italiana, onde houve o maior fluxo de imigrantes dessa etnia. Entre as suas contribuições, o estudo salienta a importância que os imigrantes de origem italiana atribuíam a escolarização. Ademais, a autora salienta que havia, por parte desse grupo, a preferência pelas escolas públicas. As chamadas escolas étnicas ligadas aos italianos tiveram, no espaço analisado, uma duração efêmera.

A leitura da obra completa é fundamental para os que se dedicam a estudar a imigração italiana, e de forma especial, obrigatória para os pesquisadores sobre a organização escolar dos imigrantes italianos. No estudo em questão, é utilizada uma multiplicidade de fontes para abordar a temática, bem como são abertas possibilidades para novas pesquisas. Assim, o livro é um convite à leitura para aqueles que se interessam pela temática em questão, assim como é uma das principais referências, do campo da História da Educação, para estudar a organização escolar entre os imigrantes italianos no RS.

\section{Referências}

ANDERSON, Benedict. Comunidades Imaginadas. 4. reimpressão. São Paulo: Companhia das Letras, 2008.

CHERVEL, André. História das disciplinas escolares: reflexões sobre um campo de pesquisa. Teoria \& Educação, v. 2, p. 177-229, 1990.

HOBSBAWM, Eric; RANGER, Terence. A invenção das tradições. São Paulo: Paz e Terra, 1997.

JULIA, D. A cultura escolar como objeto historiográfico. Revista Brasileira de História da Educação, São Paulo, v. 1, n. 1, p. 9-44, 2001. Disponível em:

<http://www.rbhe.sbhe.org.br/index.php/rbhe/article/view/273>. Acesso em: 03 mar. 2015.

LUCHESE, Terciane Ângela. O processo escolar entre imigrantes no Rio Grande do Sul. Caxias do Sul: Educs, 2015.

MAGALHÃES, Justino Pereira de. Os Arquivos e os Museus Autárquicos na Construção do Município Pedagógico. In: ENCONTRO NACIONAL DE ARQUIVOS MUNICIPAIS, 10, 2011. Leiria/Portugal. Anais... Leiria: 2011. Disponível em: <http://repositorio.ul.pt/handle/10451/5178>. Acesso em: 15 mar. 2016.

POUTIGNAT, Philippe; STREIFF-FENART, Jocelyne. Teorias da etnicidade. 2 ed. São Paulo: Unesp, 2011.

VIÑAO FRAGO, Antonio. Historia de la educación e historia cultural: posibilidades, problemas, cuestiones. Revista de Educación, Madrid, n. 306, p. 245-269, 1995. Disponível em: <redined.mecd.gob.es/xmlui/handle/11162/70501>. Acesso em: 09 jul. 2015. 
RENATA BRIÃO DE CASTRO é doutoranda no Programa de Pós-Graduação em Educação na Universidade Federal de Pelotas.

Endereço: Rua Dr. João Pessoa, 354 A - 96010-470 - Bairro Centro - Pelotas/RS - Brasil. E-mail: renatab.castro@gmail.com

PATRÍCIA WEIDUSCHADT é professora na Faculdade de Educação e no Programa de PósGraduação em Educação na Universidade Federal de Pelotas, Doutora em Educação pela Universidade do Vale do Rio dos Sinos.

Endereço: Rua Laura Lang, 321 - 96020-630 - Bairro Três Vendas - Pelotas/RS - Brasil.

E-mail: prweidus@gmail.com

Recebido em 21 de fevereiro de 2017.

Aceito em 13 de março de 2017. 